\title{
Cholera epidemic traced to risk miscalculation
}

\section{- Cancer fear led to halting of chlorination - Uncertainties in balancing risks}

\section{Washington}

A DECISION by Peruvian officials not to chlorinate much of the country's drinking water, which was based on studies by the US Environmental Protection Agency (EPA) showing that the chlorine may create a slight cancer risk, is being blamed for the devastating cholera epidemic that is now sweeping Peru and a dozen other countries in South and Central America.

Since the first incidents of cholera were identified in January, more than 300,000 new cases have been reported, mostly in Peru. Statistics released earlier this month by the Pan American Health Organization (PAHO) show that the epidemic has claimed 3,516 lives. PAHO officials believe that the bacteria first arrived with a Chinese freighter, which released its apparently contaminated bilge water into the harbour at Lima, Peru. The bacteria quickly made their way to the shellfish and fish, probably reaching humans first in the form of ceviche, a raw seafood dish popular in Peru. But once the disease appeared in humans, it quickly moved into the water supply, infecting many times as many people as might have otherwise been exposed by person-to-person contact.

US and international health officials last week blamed Peruvian water officials for a gross miscalculation in not chlorinating the entire water supply. Although Peru has good water-filtration technology and pumps safe water into the drinking water system, old pipes and open unchlorinated wells appear to have allowed the cholera bacteria to enter the water supply after filtration. Chlorine is a disinfectant and could have protected the water supply even if it were exposed to bacteria.
Yet chlorine can also react with byproducts of organic decay in the water to create several suspected carcinogens, including chloroform. A class of these chlorine-based compounds, called trihalomethanes (THMs), are currently regulated by EPA, which requires that their concentration in major water systems be less than one part per billion (p.p.b.). EPA studies in the 1970 s found that a 100 -p.p.b. level poses a cancer risk of about 1 in 10,000 .

Since then, EPA has wrestled with the question of how to balance the cancer risk of chlorination with the microbial risk of no disinfection at all (chlorine alternatives, such as ozone gas, are expensive and may have even more serious health effects). Current US regulations set a 100p.p.b. limit for THM chemicals, although one study suggests that even that level may cause 700 extra cases of cancer each year in the United States. Yet most epidemiologists agree that a relatively small risk of cancer is preferable to the possibility of a microbial epidemic.

During the 1980 s local water officials, citing the EPA studies of chlorine's cancer potential, decided to stop chlorinating many of Lima's wells. This has now raised serious questions about both EPA's risk assessment and the way it has been communicated to the rest of the world. Given the uncertainties of risk assessment and the difficulties in balancing microbial and cancer risks, researchers ask whether EPA should have given more emphasis to the disaster potential of not disinfecting water supplies.

Even if EPA was sending mixed signals, Peru appears to have heard only what it wanted to hear. Frederic Reiff, PAHO's regional director for water quality, says the decisions may have been based more on the practical and economic difficulties of chlorination than on analysis of the risks. The EPA studies "were one of a number of excuses they used to not chlorinate their water," he says. Robert Clark, director of the EPA Drinking Water Research Division, adds, "They knew the dangers. I think that they were simply using the EPA position, so they could turn around and point the finger at us and say, 'Well, they told us not to."'

This sobering case of risk assessment gone wrong is forcing US and international health officials to come to grips with the flaws in what most agree is a haphazard process of balancing real and theoretical public health risks. At a risk assessment meeting at the National Academy of Sciences in Washington last week, researchers and health organizations urged US officials to reexamine their analysis of chlorine's cancer risk in the light of the South American epidemic.

"Chlorination and disinfection of the water supplies are the pubic health success story of the century," said Carol Henry, director of the International Life Sciences Institute's (ILSI) Risk Science Institute. "To start altering this in some way has very grave and immediate consequences. I don't think we've looked at this with any rational or reasoned approach.'

Next August, ILSI will convene an international conference to discuss the problems of balancing chemical and microbial risks in water supplies. Meanwhile, the EPA, which had promised to update its chlorination standards by this year, is still wrestling with the basics: in the absence of a viable alternative to chlorination, the agency is reluctant to reduce the amount of permissible chlorine levels and risk a Peru-like epidemic. EPA officials say that they need more research to estimate chlorine's real-world risk. New regulations are not expected before the middle of the decade.

Christopher Anderson

\section{Splitting the difference on risk}

For more than ten years, two US government agencies - both charged with protecting public health, and both trying to calculate human risks based on animal tests - have disagreed on one of the most basic elements of risk assessment. The Food and Drug Administration (FDA) converts rat risks to human risks by multiplying by the difference in weight between the two species. But the Environmental Protection Agency (EPA) uses the difference in body surface area. For the same chemical, FDA would get a human risk estimate 13 times the EPA calculation. Which agency was right? No one cared. "It was a matter of turf," says EPA deputy administrator Henry Habicht. Next month, that situation will end. Conceding that US risk assessment policy is a mess, a panel of high-ranking government officials have embarked on an ambitious programme of reforms. And their first victory is the 'scaling problem'. By the end of the year, both EPA and FDA are expected to publish new procedures setting a common rule for scaling from animals to people: multiply by the difference in body weight to the three-quarters power.

Last week, the government risk assessment panel - part of the Federal
Coordinating Committee on Science Engineering and Technology (FCCSET) - held its first public meeting. More than 40 commentators - from chemical industry representatives to environmental activists - called for, among other things, better research on microbial risks (see story this page), neurotoxicity, exposure durations, animal models (fish were recommended as a replacement for rats) and risk communication.

Nearly all the commentators asked for more data and less politics, something that the FCCSET panel promised to keep in mind. 